\title{
Doses e formulações de glyphosate na cultura da soja RR
}

\section{Doses and formulations of glyphosate in RR soybean}

\author{
Rogério Farinelli ${ }^{1}$, Paschoal Alves Feres ${ }^{1}$, Hugo Dias Nunes ${ }^{1}$, Claudinei da Cruz ${ }^{1}$ \\ ${ }^{1}$ Centro Universitário da Fundação Educacional de Barretos (UNIFEB), Barretos
}

\begin{abstract}
Resumo
O trabalho teve como objetivo avaliar características agronômicas e produtivas da cultivar de soja RR aplicando doses e formulações de glyphosate. O delineamento experimental foi de blocos ao acaso, em esquema fatorial 2 × 5, constituindo 10 tratamentos e 4 repetições. Os tratamentos foram duas fontes de glyphosate (480 e $648 \mathrm{~g} \mathrm{~L}^{-1}$ de sal de isopropilamina), aplicados em doses $\left(0,0 ; 1,5 ; 2,5 ; 3,5 ; \mathrm{e} 4,5 \mathrm{~L} \mathrm{ha}^{-1} \mathrm{de}\right.$ produto comercial - p.c.). As características agronômicas avaliadas foram as seguintes: avaliações visuais de intoxicação e controle de plantas daninhas aos 7 e 14 dias após a aplicação do glyphosate, florescimento, área foliar, número de trifólios por planta, matéria seca de parte aérea e do sistema radicular, maturação fisiológica, altura de plantas e de inserção da primeira vagem, componentes da produção (número de vagens cheias e chochas por planta, número de grãos por vagem, massa de 100 grãos) e produtividade de grãos. O uso do glyphosate com maior concentração foi mais eficiente no controle das plantas daninhas nas avaliações realizadas (7 e 14 dias após aplicação). A produtividade foi afetada pelas doses de glyphosate, atingindo o valor máximo de $2.204 \mathrm{~kg} \mathrm{ha}^{-1}$ na dose estimada de $4,3 \mathrm{~L} \mathrm{ha}^{-1}$ de p.c., e não diferiu significativamente em relação aos herbicidas utilizados.
\end{abstract}

Palavras-chave: Glycine max L., transgenia, herbicida, plantas daninhas, produtividade.

\begin{abstract}
This study aims to evaluate agronomic and productive characteristics of soybean RR applying doses and formulations of glyphosate. The experimental design used was a randomized block design in a factorial pathway $2 \times 5$ with 10 treatments and 4 repetitions. The treatments are prescribed in two sources of glyphosate ( $480 \mathrm{~g} \mathrm{~L}^{-1}$ e $648 \mathrm{~g} \mathrm{~L}^{-1}$ of isopropylamine salt), applied at doses $0.0 ; 1.5 ; 2.5 ; 3.5$ e $4.5 \mathrm{~L} \mathrm{ha}^{-1}$ of a commercial product (c.p.). The agronomic characteristics evaluated were visual evaluations of intoxication and weed control at 7 and 14 days after the glyphosate application, number of days to flowering, the leaf area, number of trifoliate leaves per plant, the dry matter weight of shoot and root plants, physiological maturity, plant and first pod insertion height, production components (number of pods and empty pods per plant and seeds per pod, weight of 100 grains) and grain productivity. The use of glyphosate with the highest concentration was more effective in controlling weeds ( 7 and 14 days after application). The yield was affected by glyphosate doses, reaching a maximum value of $2.204 \mathrm{~kg} \mathrm{ha}^{-1}$ in the estimated dose of 4.3 $\mathrm{L} \mathrm{ha}^{-1}$ p.c.
\end{abstract}

Keywords: Glycine max L., transgenic, herbicide, weed seed, yields.

Autor para correspondência: Rogério Farinelli - Av. Prof. Roberto Frade Monte, 389 - Aeroporto - CEP: 14784-226, Barretos (SP), Brasil. E-mail: rogerio.farinelli@unifeb.edu.br

Recebido em: 20 de janeiro de 2020

Aceito para publicação em: 07 de maio de 2020

https://doi.org/10.4322/1980-0029.122020 


\section{Introdução}

A soja (Glycine max (L.) Merrill) é considerada a mais importante oleaginosa do mundo e uma das mais importantes no Brasil, empregada tanto para consumo animal quanto na alimentação humana, com consumo in natura ou em produtos derivados.

Por tratar-se da principal cultura do país e caracterizada como commodity agrícola, o tratamento fitossanitário é muito empregado nas lavouras, sendo que o uso desses produtos para o controle de plantas daninhas constitui-se como método mais eficiente, e em grandes áreas o mais econômico. O surgimento da soja resistente ao herbicida glyphosate (Roundup Ready ${ }^{\circledR}$ ), denominada comumente de soja RR, provocou mudanças marcantes no manejo das plantas daninhas nessa cultura. Antes do advento dessa tecnologia, eram utilizados muitos herbicidas pertencentes a vários ingredientes ativos, tanto em aplicações isoladas quanto em misturas formuladas. Contudo, com a soja transgênica, usa-se o ingrediente ativo glyphosate, salvo nos locais onde há problemas de plantas daninhas tolerantes ou resistentes a esse princípio ativo, tornando-se necessários outros métodos de controle ou mesmo mistura de herbicidas (Empresa Brasileira de Pesquisa Agropecuária, 2008).

Na soja RR, o glyphosate pode ser utilizado em aplicações únicas ou sequenciais, em doses e épocas que irão variar conforme as espécies e populações de plantas daninhas presentes na lavoura e também da tecnologia de aplicação do produtor. Outro fator que pode alterar o controle de plantas daninhas e a seletividade à cultura é a época de aplicação do glyphosate. Aplicações em estádio inicial podem proporcionar reinfestação das plantas daninhas, enquanto a aplicação em estádio avançado de desenvolvimento reduz o controle de espécies infestantes e permite a competição de plantas daninhas com a cultura no início de seu ciclo (Vila-Aiub et al., 2008).

Embora haja esse mecanismo de resistência, Santos et al. (2007) afirmaram possível efeito do glyphosate afetando negativamente o desenvolvimento inicial de plantas de soja, para a qual esse produto é recomendado. Os mesmos autores supõem que estes efeitos negativos podem estar relacionados ao aumento demasiado da dose aplicada, à aplicação de outras formulações do produto não recomendados ou ao efeito de outras substâncias químicas naturais ou sintéticas usadas como surfactantes (responsáveis por diminuir a tensão superficial da gota e espalhar o produto de forma uniforme).

Fato comprovado por Reis et al. (2010), que verificaram que doses acima do recomendado, independentemente da formulação utilizada, promovem efeitos fitotóxicos em soja transgênica, os quais são mais acentuados na formulação Roundup Transorb, com 55,5\% da área foliar acometida. Os resultados demonstraram que, nas avaliações, o tratamento com Transorb $®$ também apresentou menor número de folhas comparado a sua testemunha e ao tratamento com Zapp Qi ${ }^{\circledR}$ e Roundup Original ${ }^{\circledR}$, porém o seu índice de matéria seca da parte aérea foi maior que o tratamento com Zapp Qi ${ }^{\circledR}$ e não diferiram entre si nas dosagens estudadas.

Já Agostinetto et al. (2009a) relataram no trabalho desenvolvido com soja RR que o glyphosate nas formulações testadas (Roundup Ready $^{\circledR}$ e Roundup Transorb ${ }^{\circledR}$, Roundup $W^{\circledR}{ }^{\circledR}$ e Zapp $\mathrm{Qi}^{\circledR}$ ) na dose de $720 \mathrm{~g} \mathrm{ha}^{-1}$ de equivalente ácido foi seletivo às cultivares BRS 244 RR e M-SOY 7979 RR. A produtividade de grãos variou entre as cultivares de soja e não diferiu entre as formulações, sendo superior quando a aplicação foi realizada aos 35 e 50 d.a.e. (dias após a emergência), comparativamente a 20 d.a.e. Isso pode ser consequência da competição exercida pelas plantas daninhas que emergiram após a aplicação do herbicida, na fase inicial de desenvolvimento da cultura, uma vez que o glyphosate não apresenta efeito residual.

Pinto et al. (2016) observaram que diferentes doses de glifosato $\left(540,1080\right.$ e 2160 g i.a. ha $\left.{ }^{-1}\right)$ em diferentes épocas de aplicação (V3/V4, V8 e R7) não interferiram nos atributos produtivos e na qualidade fisiológica das sementes de soja da cultivar BRS Valiosa RR, exceto pelo número de vagens por planta e comprimento de raiz primária na dose 2160 g i.a. ha-1 de glifosato em V8.

Sendo assim, o objetivo deste trabalho foi avaliar os componentes da produção, produtividade da soja RR, como também controle de plantas daninhas e intoxicação de plantas de soja aplicando doses e formulações de glyphosate.

\section{Material e Métodos}

O experimento foi instalado durante a safra primavera-verão 2013/2014, em área experimental do Centro Universitário da Fundação Educacional 
de Barretos-UNIFEB, em um solo classificado como Latossolo Vermelho distrófico, apresentando

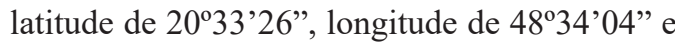
altitude de 530 metros. Segundo a classificação de Köeppen, o clima da região é do tipo Cwa, sendo definido como tropical de altitude, com inverno seco e verão quente e chuvoso, obtendo uma precipitação de $555 \mathrm{~mm}$ durante o ciclo da cultura, com média de $5,4 \mathrm{~mm}$ por dia.

Os resultados da análise química do solo da área experimental, na profundidade de $0-20 \mathrm{~cm}$, apresentaram os seguintes valores: $\mathrm{pH}\left(\mathrm{CaCl}_{2}\right)=5,5$; M.O. $\left(\mathrm{g} \mathrm{kg}^{-1}\right)=26 ; \mathrm{P}\left(\mathrm{mg} \mathrm{dm}^{-3}\right)=3 ; \mathrm{K}\left(\mathrm{mmol} \mathrm{dm}^{-3}\right)=3,4$; $\mathrm{Ca}\left(\mathrm{mmol}_{\mathrm{c}} \mathrm{dm}^{-3}\right)=28 ; \mathrm{Mg}\left(\mathrm{mmol}_{\mathrm{c}} \mathrm{dm}^{-3}\right)=13 ; \mathrm{H}+\mathrm{Al}$ $\left(\mathrm{mmol}_{\mathrm{c}} \mathrm{dm}^{-3}\right)=24,9 ; \mathrm{SB}\left(\mathrm{mmol}_{\mathrm{c}} \mathrm{dm}^{-3}\right)=44,4$; CTC $\left(\mathrm{mmol}_{\mathrm{c}} \mathrm{dm}^{-3}\right)=69,4 ; \mathrm{e} \mathrm{V}(\%)=64$.

Como a soja foi cultivada em área anteriormente em pousio, antes da instalação do experimento foi realizado um levantamento das espécies de plantas daninhas, com a finalidade de obter conhecimento de quais estavam presentes na área. Com o levantamento, foram constatadas a infestação de fedegoso (Senna occidentalis), dorme-dorme (Mimosa pudica), corda-de-viola (Ipomoea sp.), brachiaria (Urocloa decumbens), tiririca (Cyperus rotundus), guanxuma (Sida sp.), carrapichão (Xanthium strumarium), capim carrapicho (Cenchrus echinatus), picão preto (Bidens pilosa), capim colonião (Panicum maximum) e trapoeraba (Commelina benghalensis).

O solo foi preparado de forma convencional, com grade intermediária, aração e, na sequência, duas gradagens niveladoras. A adubação mineral de semeadura efetuada foi de $340 \mathrm{~kg} \mathrm{ha}^{-1}$ do formulado $02-20-10+0,3 \% \mathrm{~B}$ e $0,2 \% \mathrm{Zn}$, levando-se em consideração os resultados da análise química do solo e algumas recomendações técnicas, como a textura do solo, profundidade da análise do solo e estimativa de produtividade.

A semeadura foi efetuada em 6 de dezembro de 2013 manualmente em sulcos previamente abertos e adubados com auxílio de semeadora-adubadora utilizando espaçamentos entre linha de $0,50 \mathrm{~m}$ e uma densidade de 20 sementes por metro, para uma população inicial de 400 mil plantas por ha-1 .

O delineamento experimental foi de blocos ao acaso (DBC) em esquema fatorial $2 \times 5$, constituindo 10 tratamentos com 4 repetições, totalizando 40 parcelas. Os tratamentos prescrevem-se em duas fontes de glyphosate $\left(480 \mathrm{~g} \mathrm{~L}^{-1}\right.$ e $648 \mathrm{~g} \mathrm{~L}^{-1}$ de sal de isopropilamina) aplicados em cinco doses 0,0 ;
1,$5 ; 2,5 ; 3,5 ; \mathrm{e} 4,5 \mathrm{~L} \mathrm{ha}^{-1}$ de produto comercial e o controle com aplicação de água. Cada parcela foi composta por 6 linhas de $5 \mathrm{~m}$ de comprimento, com $1 \mathrm{~m}$ entre parcelas, considerando para área útil as 4 linhas centrais, desprezando-se $0,50 \mathrm{~m}$ de cada extremidade.

A cultivar de soja utilizada foi a BMX Potência $\mathrm{RR}$, que possui como características: ciclo semiprecoce, crescimento indeterminado, flores brancas e pubescência cinza, hilo de coloração marrom claro, além de ser resistente ao nematoide do cisto (raça 3), resistente ao acamamento, ao glyphosate e necessita de fertilidade do solo de média a alta.

A aplicação das doses de glyphosate foi realizada em pós-emergência da cultura da soja no estádio V4 (15 d.a.e - 15 dias após a emergência), caracterizado na formação do terceiro trifólio da planta, utilizando um pulverizador costal pressurizado a $\mathrm{CO}_{2}$ à pressão constante de $30 \mathrm{lb}$ pol $^{-2}$, com ponta de pulverização tipo leque XR 110:02, espaçadas a $0,50 \mathrm{~m}$ e com consumo de calda de $200 \mathrm{~L} \mathrm{ha}^{-1}$.

Os demais manejos fitossanitários foram realizados mediante o acompanhamento, utilizando produtos recomendados à cultura da soja.

Durante a condução do experimento, foram avaliados os sintomas visuais de intoxicação na soja e avalições de controle, ambos realizados aos 7 e 14 dias após a aplicação (daa). Para as avaliações de intoxicação, foi atribuída a cada unidade experimental uma nota, utilizando-se a escala de valores proposta pela European Weed Research Council (1964), em que 1 = nenhuma injúria e $9=$ morte da planta. Já para as avaliações de controle, utilizou-se a escala visual escala visual (European Weed Research Council, 1964) de $0 \%$ a $100 \%$ (ausência de controle e controle total das plantas daninhas, respectivamente), cuja nota é atribuída à comunidade infestante em geral na parcela.

No estádio R2 (florescimento pleno), foi avaliada em dez plantas ao acaso, por parcela, a área foliar (AF), utilizando os parâmetros de comprimento máximo do limbo (C), a largura máxima perpendicular à nervura principal do limbo foliar (L) e o produto do comprimento pela largura $(\mathrm{AF}=\mathrm{CxL})$. Também neste estádio, foi realizada a avaliação do número de trifólios por planta, realizando a contagem dos trifólios em dez plantas ao acaso por parcela. 
Na maturação fisiológica (estádio R8), foram coletadas dez plantas ao acaso, por parcela, para as seguintes determinações: altura de plantas, medindo-se a distância entre o colo da planta à extremidade apical da haste principal, e a distância entre o colo da planta e a inserção da primeira vagem, respectivamente. Posteriormente, avaliaram-se o número de vagens por planta e o número de grãos por planta, pela relação entre o número total de vagens e o número total de plantas, e a relação entre o número total de grãos e o número total de vagens, respectivamente.

A massa de 1000 grãos foi determinada através da contagem de 2 subamostras de 1000 grãos casualizados por parcela experimental e a seguir realizaram-se as pesagens. Já a produtividade de grãos foi realizada colhendo-se as plantas da área útil de cada parcela experimental, com posterior trilha mecânica e pesagem dos grãos, sendo os dados obtidos transformados em $\mathrm{kg} \mathrm{ha}^{-1}$, a $13 \%$ de umidade $((\mathrm{U} \%=(\mathrm{Pi}-\mathrm{Pf}) / \mathrm{Pi}-\mathrm{T}) \times 100)$, onde $\mathrm{P} i=$ Peso inicial sementes, $\mathrm{Pf}=$ Peso final sementes, $\mathrm{T}=$ Peso recipiente, determinado por meio do método da estufa a $105^{\circ} \mathrm{C} \pm 3^{\circ} \mathrm{C}$ por 24 horas (Brasil, 2009).

Os resultados foram submetidos à análise de variância, empregando-se o teste $\mathrm{F}$, e para a comparação dos valores obtidos para as fontes de glyphosate foi utilizado o teste de Tukey a $5 \%$ de probabilidade e análise de regressão polinomial para a comparação dos valores das doses, bem como as interações significativas.

\section{Resultados e Discussão}

Nas avaliações visuais de fitointoxicação, não foram constatadas injúrias nas plantas de soja em nenhum dos tratamentos (Tabela 1). Foloni et al. (2005) observaram em soja RR que apenas aos 20 d.a.a (20 dias após a aplicação) ocorreram sintomas de fitointoxicação, sendo este muito leve em todos os tratamentos com glyphosate (648 $\left.\mathrm{g} \mathrm{L}^{-1}\right)$, nas doses variando de 0 a 2,2 $\mathrm{L} \mathrm{ha}^{-1}$ de p.c., mostrando ser a cultura altamente seletiva a este herbicida.

Reis et al. (2010) observaram sintomas de intoxicação em soja RR em virtude da aplicação de diversas formulações de glyphosate. Os modelos que mais se adequaram aos dados foi o modelo cúbico, no qual pôde ser observado que a formulação Transorb obteve maior efeito sobre o Zapp Qi, atingindo a nota 3,25, o que corresponde a $65,0 \%$ de área foliar acometida por fitoxidade. De acordo com Santos et al. (2007), a aplicação de qualquer herbicida sobre as plantas de soja causa algum tipo de estresse, porém este pode ser mais pronunciado, dependendo do genótipo.

Tabela 1. Controle de plantas daninhas, área foliar e número de trifólios por planta na cultura da soja transgênica RR em função de diferentes doses de herbicidas à base de glyphosate.

\begin{tabular}{|c|c|c|c|c|}
\hline \multirow{3}{*}{ Tratamentos } & \multicolumn{2}{|c|}{ Controle de plantas daninhas } & \multirow{2}{*}{ Área foliar } & \multirow{2}{*}{$\begin{array}{l}\text { Trifólios por } \\
\text { planta }\end{array}$} \\
\hline & (7 d.a.a) & (14 d.a.a) & & \\
\hline & \multicolumn{2}{|c|}{-----(\%)---- } & $\left(\mathrm{cm}^{2}\right)$ & $\left(n^{0}\right)$ \\
\hline \multicolumn{5}{|c|}{ Doses de glyphosate (D) } \\
\hline $0 \mathrm{~L} \mathrm{ha}^{-1}$ & $0,0^{(1)}$ & $0,0^{(2)}$ & 50,4 & 14,0 \\
\hline $1,5 \mathrm{~L} \mathrm{ha}^{-1}$ & 81,2 & 71,2 & 52,1 & 14,0 \\
\hline $2,5 \mathrm{~L} \mathrm{ha}^{-1}$ & 90,3 & 81,4 & 54,1 & 16,0 \\
\hline $3,5 \mathrm{~L} \mathrm{ha}^{-1}$ & 97,9 & 90,8 & 53,4 & 14,0 \\
\hline $4,5 \mathrm{~L} \mathrm{ha}^{-1}$ & 90,1 & 87,9 & 56,3 & 17,0 \\
\hline Teste F & $14,16^{* *}$ & $9,79 * *$ & $1,02^{\mathrm{ns}}$ & $2,12^{\mathrm{ns}}$ \\
\hline \multicolumn{5}{|l|}{ Formulações (F) } \\
\hline $480 \mathrm{~g} \mathrm{~L}^{-1}$ & $68,0 \mathrm{~b}$ & $61,7 \mathrm{~b}$ & $54,5 \mathrm{a}$ & $15,0 \mathrm{a}$ \\
\hline $648 \mathrm{~g} \mathrm{~L}^{-1}$ & $72,0 \mathrm{a}$ & $67,5 \mathrm{a}$ & $52,1 \mathrm{a}$ & $15,0 \mathrm{a}$ \\
\hline Teste F & $1.108,21 * *$ & $327,16^{* *}$ & $0,77^{\text {ns }}$ & $0,001^{\mathrm{ns}}$ \\
\hline \multicolumn{5}{|l|}{$\mathrm{D} \times \mathrm{F}$} \\
\hline Teste F & $2,54^{\mathrm{ns}}$ & $1,46^{\mathrm{ns}}$ & $0,41^{\text {ns }}$ & $0,41^{\text {ns }}$ \\
\hline Média geral & 70,0 & 64,62 & 53,33 & 15,0 \\
\hline CV $(\%)$ & 4,80 & 8,99 & 13,67 & 17,44 \\
\hline
\end{tabular}

Médias seguidas de letras distintas diferem entre si pelo Teste de Tukey $(\mathrm{p}<0,05)$. ${ }^{\text {ns }}$ não significativo; * significativo a $5 \%$; $\mathrm{e}^{* *}$ significativo a $1 \%$. $^{(1)} \mathrm{y}=-7,66 \mathrm{x}^{2}+53,88 \mathrm{x}+4,28 \mathrm{R}^{2}=0,94 * * ;{ }^{(2)} \mathrm{y}=-6,19 \mathrm{x}^{2}+46,65 \mathrm{x}+3,43 \mathrm{R}^{2}=0,95 * *$. 
Em relação às avaliações de controle de plantas daninhas, a dose que obteve maior eficiência foi a de 3,5 $\mathrm{L} \mathrm{ha}^{-1}$ de p.c. com $97 \%$ aos 7 d.a.a e $90 \%$ aos 14 d.a.a., e a que obteve menor eficiência foi a de $1,5 \mathrm{~L} \mathrm{ha}^{-1} \operatorname{com} 81 \%$ aos 7 d.a.a. e $71 \%$ aos 14 d.a.a. O glyphosate na concentração de $648 \mathrm{~g}$ $\mathrm{L}^{-1}$ de sal de isopropilamina foi o mais eficiente quando comparado com o de $480 \mathrm{~g} \mathrm{~L}^{-1}$ (Tabela 1). Resultados semelhantes foram obtidos por Foloni et al. (2005) para todas as doses individuais a partir de 1,0 L ha-1 de p.c., com controle igual ou superior a $90 \%$ das plantas infestantes, aos 20 d.a.a. A aplicação de 1,3 $\mathrm{L} \mathrm{ha}^{-1}$ proporcionou controle de $81,3 \%$, sendo este inferior aos obtidos com as doses de 1,5 e 1,8 $\mathrm{L} \mathrm{ha}^{-1}$.

A área foliar e o número de trifólios por planta não foram influenciados pelos produtos ou doses, tendo obtido valor médio de $53,33 \mathrm{~cm}^{2}$ e de 15 trifólios por planta, respectivamente (Tabela 1).

A ausência de fitointoxicação do glyphosate e consequentemente a ausência de efeito nos parâmetros morfofisiológicos nas doses acima do recomendado que se situa até $2,5 \mathrm{~L} \mathrm{ha}^{-1}$ de p.c. (648 $\mathrm{g} \mathrm{L}^{-1}$ de sal de isopropilamina) não corrobora com Santos et al. (2007), que verificaram efeito de três formulações de glyphosate sobre soja RR e constataram que a aplicação do herbicida reduziu o número de folíolos e rendimento, além de aumentar a fitointoxicação das plantas.

Tal resultado também não se assemelha ao obtido por Reis et.al. (2010), pois além do maior aspecto visual de fitotoxidade, os resultados demonstraram que a formulação Transorb, ao contrário do Zapp Qi, apresentou uma redução linear no número de folhas, com uma diferença de $48 \%$ entre a maior dose e a testemunha.

Em relação à altura de plantas, tanto as doses como as formulações não influenciaram significativamente os resultados (Tabela 2). Correia \& Durigan (2007) afirmaram, quanto ao uso dos herbicidas (Roundup Ready, Roundup Transorb, Roundup Original, Roundup WG, Polaris, Gliz, Glifosato Nortox e Trop) em cultivares de soja RR, que não ocorreu influência no desenvolvimento vegetativo das plantas, no que diz respeito à altura de plantas e de nós por planta. Além disso, a diferença em relação ao porte da planta e à altura de vagem pode ser influenciada por fatores ambientais como temperatura, veranicos, altitude, latitude e/ou práticas culturais como preparo do solo na época de semeadura e está fortemente relacionada com as cultivares de soja (Heiffig \& Câmara, 2006).

Tabela 2. Altura de planta, altura de inserção de primeira vagem, número de vagens por planta e número de grãos por vagem na cultura da soja transgênica RR em função de diferentes doses de herbicidas à base de glyphosate.

\begin{tabular}{|c|c|c|c|c|}
\hline \multirow[t]{2}{*}{ Tratamentos } & Altura de planta & $\begin{array}{c}\text { Altura de } \\
\text { inserção de } \\
\text { primeira vagem }\end{array}$ & Vagens por planta & Grãos por vagem \\
\hline & ----------(c & |)--------- & --------(1 & o)------- \\
\hline
\end{tabular}

Doses de glyphosate (D)

\begin{tabular}{|c|c|c|c|c|}
\hline $0 \mathrm{~L} \mathrm{ha}^{-1}$ & 68,2 & $5,7^{(1)}$ & $13,2^{(2)}$ & $1,8^{(3)}$ \\
\hline $1,5 \mathrm{~L} \mathrm{ha}^{-1}$ & 69,6 & 6,1 & 20,8 & 1,9 \\
\hline $2,5 \mathrm{~L} \mathrm{ha}^{-1}$ & 68,7 & 6,5 & 22,4 & 2,0 \\
\hline $3,5 \mathrm{~L} \mathrm{ha}^{-1}$ & 69,7 & 6,8 & 21,3 & 2,1 \\
\hline $4,5 \mathrm{~L} \mathrm{ha}^{-1}$ & 68,9 & 7,1 & 17,4 & 2,2 \\
\hline Teste F & $0,019^{\mathrm{ns}}$ & $4,52 * *$ & $3,96 * *$ & $10,43 * *$ \\
\hline \multicolumn{5}{|c|}{ Formulações (F) } \\
\hline $480 \mathrm{~g} \mathrm{~L}^{-1}$ & $69,1 \mathrm{a}$ & $6,5 \mathrm{a}$ & $18,7 \mathrm{a}$ & $2,0 \mathrm{a}$ \\
\hline $648 \mathrm{~g} \mathrm{~L}^{-1}$ & $68,9 \mathrm{a}$ & $6,4 \mathrm{a}$ & $19,4 \mathrm{a}$ & $1,9 \mathrm{a}$ \\
\hline Teste F & $0,26^{\mathrm{ns}}$ & $0,16^{\mathrm{ns}}$ & $0,17^{\mathrm{ns}}$ & $1,06^{\mathrm{ns}}$ \\
\hline \multicolumn{5}{|l|}{$\mathrm{D} \times \mathrm{F}$} \\
\hline Teste F & $1,70^{\mathrm{ns}}$ & $0,51^{\mathrm{ns}}$ & $1,45^{\mathrm{ns}}$ & $0,50^{\mathrm{ns}}$ \\
\hline Média & 69,0 & 6,5 & 19,0 & 2,0 \\
\hline CV (\%) & 9,29 & 11,90 & 29,46 & 7,59 \\
\hline
\end{tabular}

Médias seguidas de letras distintas diferem entre si pelo Teste de Tukey $(\mathrm{p}<0,05)$. ${ }^{\text {ns }}$ não significativo; * significativo a $5 \%$; e* significativo a $1 \%$. $\left.{ }^{(1)} \mathrm{y}=0,32 \mathrm{x}+5,7 \mathrm{R}^{2}=0,96^{* *} ;{ }^{(2)} \mathrm{y}=-1,37 \mathrm{x}^{2}+7,12 \mathrm{x}+13,2 \mathrm{R}^{2}=0,90 * * ;{ }^{*}\right) \mathrm{y}=0,08 \mathrm{x}+1,8$ $\mathrm{R}^{2}=0,69 * *$. 
$\mathrm{Na}$ altura de inserção de primeira vagem (Tabela 2), houve efeito significativo das doses, sendo o maior resultado mediante a aplicação de 4,5 $\mathrm{L} \mathrm{ha}^{-1}$ de p.c.

A altura de inserção de primeira vagem foi baixa neste estudo por motivos climáticos, devido às temperaturas elevadas, e precipitações abaixo da média. De acordo com Rezende \& Carvalho (2007), alturas de inserções de vagem de, pelo menos, 10 a $12 \mathrm{~cm}$ tornam-se adequadas à mecanização da colheita. Porém, para a maioria das lavouras de soja, a altura de inserção da vagem mais satisfatória está em torno de $15 \mathrm{~cm}$, embora as colhedoras mais modernas possam efetuar a colheita com plantas apresentando altura de inserção em torno de $10 \mathrm{~cm}$.

Quanto ao número de vagens por planta e grãos por vagem, novamente as formulações não influenciaram, mas as doses afetaram positivamente para o número de grãos por vagem, aumentando-o conforme a elevação das doses aplicadas, obtendo efeito linear. Em relação ao número de vagens por planta, houve efeito quadrático, estabelecendo uma produção de 22,4 vagens por planta com aplicação de aproximadamente $2,6 \mathrm{~L} \mathrm{ha}^{-1}$ de p.c. (Tabela 2).

Conforme Agostinetto et al. (2009a), independentemente da dose, as aplicações efetuadas aos 50 dias após emergência, em comparação às demais épocas ( 25 e 35 d.a.e.), promoveram maior número de vagens por planta, em consequência da competição exercida pelas plantas daninhas que emergiram após a aplicação do herbicida, na fase inicial de desenvolvimento da cultura, uma vez que o glyphosate não apresenta efeito residual.

Melhorança Filho et al. (2010) verificaram que a maior dose comercial de glyphosate (Gliz ${ }^{\circledR}$ - $1.800 \mathrm{~g} \mathrm{e} . \mathrm{a} \mathrm{ha}^{-1}$ ) reduziu a altura, o número de vagens planta por planta e a produtividade de grãos da cultivar CD-212 RR. Ressalta-se que, em termos médios, já a aplicação de dose de 720 g e.a ha ${ }^{-1}$ glyphosate determinou decréscimos da ordem de $8,3 \%$, e para as doses de 1080 , 1440 e 1800 g e.a ha ${ }^{-1}$ foi de $3,4 \%, 8,8 \%$ e $21 \%$, respectivamente.

Em relação à massa de 1000 grãos e produtividade de grãos, também não houve efeito dos produtos estudados, mas houve influência nas doses aplicadas. Os valores para a massa de 1000 grãos tiveram acréscimo até $3,5 \mathrm{~L} \mathrm{ha}^{-1}$ de p.c., após esta dose ocorreu um decréscimo (Tabela 3 ).

Em relação à produtividade de grãos, independentemente da formulação, também ocorreu ajuste quadrático, contudo, a dose estimada de 4,3 $\mathrm{L} \mathrm{ha}^{-1}$ de p.c. permitiu alcançar a máxima produtividade de $2.204 \mathrm{~kg} \mathrm{ha}^{-1}$ (Figura 1). Esta dose está acima das recomendações para soja RR, quando se trata de aplicações únicas, em que o glyphosate (concentração de $648 \mathrm{~g} \mathrm{~L}^{-1}$ de sal de isopropilamina) pode ser utilizado em doses de 1,2 a $2,5 \mathrm{~L} \mathrm{ha}^{-1}$ de p.c.

Tabela 3. Massa de 100 grãos e produtividade de grãos na cultura da soja transgênica RR em função de diferentes doses de herbicidas à base de glyphosate.

\begin{tabular}{lcc}
\hline \multicolumn{1}{c}{ Tratamentos } & Massa de $\mathbf{1 0 0 0}$ grãos (g) & Produtividade de grãos (kg ha-1) \\
\hline Doses de glyphosate (D) & $97^{(1)}$ & $601^{(2)}$ \\
$0 \mathrm{~L} \mathrm{ha}^{-1}$ & 123 & 1548 \\
$1,5 \mathrm{~L} \mathrm{ha}^{-1}$ & 133 & 1792 \\
$2,5 \mathrm{~L} \mathrm{ha}^{-1}$ & 136 & 2270 \\
$3,5 \mathrm{~L} \mathrm{ha}^{-1}$ & 132 & 2164 \\
$4,5 \mathrm{~L} \mathrm{ha}^{-1}$ & $11,03^{* *}$ & $52,33^{* *}$ \\
Teste F & & \\
Formulações (F) & $125 \mathrm{a}$ & $2814 \mathrm{a}$ \\
$480 \mathrm{~g} \mathrm{~L}^{-1}$ & $123 \mathrm{a}$ & $2863 \mathrm{a}$ \\
$648 \mathrm{~g} \mathrm{~L}^{-1}$ & $0,14^{\mathrm{ns}}$ & $1,43^{\mathrm{ns}}$ \\
Teste F & & \\
D x F & $0,37^{\mathrm{ns}}$ & $2,10^{\mathrm{ns}}$ \\
Teste F & 124,2 & 1675 \\
Média & 12,17 & 15,52 \\
CV $(\%)$ & & \\
\hline
\end{tabular}

Médias seguidas de letras distintas diferem entre si pelo Teste de Tukey $(\mathrm{p}<0,05)$. ${ }^{\text {ns }}$ não significativo; * significativo a $5 \%$; $e^{* *}$ significativo a $1 \% .{ }^{(1)} \mathrm{y}=-0,32 \mathrm{x}^{2}+2,27 \mathrm{x}+9,6 \mathrm{R}^{2}=0,85 * * ;{ }^{(2)} \mathrm{y}=-86,661 \mathrm{x}^{2}+744,86 \mathrm{x}+604,34 \mathrm{R}^{2}=0,99 * *$. 


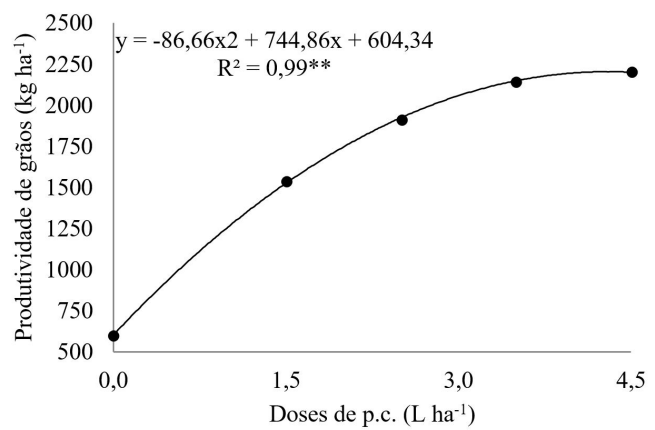

Figura 1. Produtividade de grãos da cultura da soja transgênica RR em função de diferentes doses de herbicidas à base de glyphosate.

Isto reflete o que está ocorrendo em lavouras comerciais na região Norte do Estado de São Paulo, onde a recomendação para a aplicação de glyphosate em soja RR ultrapassa as doses oficiais do produto, muitas vezes pela falta de conhecimento das plantas daninhas presentes na área, estádio de aplicação, baixo custo do herbicida e principalmente pela ausência de fitotoxicidade nas plantas de soja.

Os resultados para os componentes da produção, e principalmente para a produtividade, foram baixos em virtude das condições climáticas muito adversas, como falta de precipitação com estiagem de mais de 35 dias, associada às temperaturas muito altas (acima de $35^{\circ} \mathrm{C}$ ), principalmente nos estádios fenológicos de formação de vagens e enchimento de grãos (R4 e R5). O índice pluviométrico mostrou que no mês de janeiro de 2013 ocorreu um acúmulo de $298 \mathrm{~mm}$ e em janeiro de 2014 apenas $73 \mathrm{~mm}$. Este déficit de $215 \mathrm{~mm}$ afetou significativamente o rendimento da cultura da soja na região Norte do Estado de São Paulo.

Mulugueta \& Boerboom (2000) verificaram que a aplicação do glyphosate nos estádios vegetativos da soja (V2 e V4) proporcionou maior produtividade à cultura. Já Zadinello et al. (2012) relataram redução na produtividade de $15 \%$ quando o herbicida foi aplicado no estádio $\mathrm{R} 2$ em relação à testemunha; $3,27 \%$ no estádio R4; e $0,8 \%$ no estádio R5.

Em outro trabalho, Agostinetto et al. (2009b) verificaram que a produtividade de grãos variou somente entre as cultivares de soja RR e não diferiu entre as formulações, sendo superior quando a aplicação foi realizada aos 35 e 50 d.a.e, comparativamente aos 20 d.a.e. Isso pode ser consequência da competição exercida pelas plantas daninhas que emergiram após a aplicação do herbicida, na fase inicial de desenvolvimento da cultura, uma vez que o glyphosate não apresenta efeito residual.

\section{Conclusões}

O glyphosate de concentração de $648 \mathrm{~g} \mathrm{~L}^{-1}$ de sal de isopropilamina foi o mais eficiente no manejo das plantas daninhas nas duas épocas de avaliação, tanto aos 7 quanto aos 14 dias após aplicação.

As produtividades foram afetadas pelas doses de glyphosate, atingindo o valor máximo de $2204 \mathrm{~kg} \mathrm{ha}^{-1}$ na dose estimada de 4,3 $\mathrm{L} \mathrm{ha}^{-1}$ de p.c., e não diferiu significativamente em relação aos herbicidas utilizados.

\section{Referências}

Agostinetto, D., Al Magro, T., Galon, L., Moraes, P. V. D. \& Tironi, S. P. (2009a). Resposta de cultivares de soja transgênica e controle de plantas daninhas em função de épocas de aplicação e formulações de glyphosate. Planta Daninha, 27(4), 739-746.

Agostinetto, D., Tironi, S. P., Galon, L., \& Dal Magro, T. (2009b). Desempenho de formulações e doses de glyphosate em soja transgênica. Revista Trópica, 3(2), 35-41.

Brasil. (2009). Ministério da Agricultura. Determinação do grau de umidade. Regras para análise de sementes, Brasília: Ministério da Agricultura.

Correia, N. M., \& Durigan, J. C. (2007). Seletividade de diferentes herbicidas à base de glyphosate a soja RR. Planta Daninha, 25(2), 375-379.

Empresa Brasileira de Pesquisa Agropecuária EMBRAPA. (2008). Tecnologias de produção de soja - região central do Brasil - 2008. Londrina: Embrapa Soja, Embrapa Cerrados, Embrapa Agropecuária Oeste.

European Weed Research Council - EWRC. (1964). Report of 3rd and 4rd meetings of EWRC - Comittee of methods in weed research. Weed Research, 4(1), 88. 
Foloni, L. L., Rodrigues, D., Ferreira, F., Miranda, R., \& Ono, E. O. (2005). Aplicação de glifosato em pós-emergência, em soja transgênica cultivada no cerrado. Revista Brasileira de Herbicidas, 3(3), 47-58.

Heiffig, L. S., \& Câmara, G. M. S. (2006). Soja: colheita e perdas (Série: Produtor Rural). Piracicaba: ESALQ - Divisão de Biblioteca e Documentação.

Melhorança Filho, A. L., Martins, D., Pereira, M. R. R., \& Espinosa, W. R. (2010). Efeito de glyphosate sobre características produtivas em cultivares de soja transgênica e convencional. Bioscience Journal, 26(3), 322-333.

Mulugueta, D., \& Boerboom, C. M. (2000). Critical time of weed removal in glyphosate-resistant Glycine max. Weed Science, 42(1), 35-42.

Pinto, C. C., Oliveira, C. O., Américo, G. H. P., Vazquez, G. H., \& Lazarini, E. (2016). Efeito da dose e da época de aplicação do glifosato na produção e na qualidade da soja RR. Revista de Ciências Agrárias (Belém), 39(2), 310-317.
Reis, T.C., Neves, A.F., Andrade, A.P., \& Santos, T. S. (2010). Efeitos de fitotoxidade na soja RR tratada com formulações e dosagens de glifosato. Revista de Biologia e Ciências da Terra, 10(1), 34-43.

Rezende, P. M., \& Carvalho, E. A. (2007). Avaliação de cultivares de soja (Glycine max). Ciência e Agrotecnologia, 31(6), 1616-1623.

Santos, J. B., Ferreira, E.A., Reis, M.R., Silva, A.A., Fialho, C.M.T. \& Freitas, M. A. M. (2007). Avaliação de formulações de glyphosate sobre soja Roundup Ready. Planta Daninha, 25(1), 165-171.

Vila-Aiub, M. M., Vidal, R. A., Balbi, M. C., Gundel, P. E., Trucco, F., \& Ghersa, C. M. (2008). Glyphosate-resistant weeds of South American cropping systems: an overview. Pest Management Science, 64(1), 366-371.

Zadinello, R., Chaves, M. M., Santos, R. F., Bassegio, D., \& Werncke, I. (2012). Influência da aplicação de glifosato na produtividade da soja. Acta Iguazu, 1(4), 1-8. 